\title{
Environmental Impact Assessment of Power Development Project: Lessons from Thailand Experiences
}

\author{
Chesoh, Sarawuth, $\mathrm{PhD}$ \\ Pattani Fisheries Research and Development Center, Pattani \\ Department of Fisheries, 94160, Thailand \\ Tel: 66-73-468-826 E-mail: chesoh.s@hotmail.com
}

Received: April 10, $2011 \quad$ Accepted: May 8, $2011 \quad$ doi:10.5539/ass.v7n9p119

\begin{abstract}
Environmental impact assessment (EIA) is an important part of environmental and public health regulations. Increasing demand of electric consumption in Thailand is a major challenge for authorities trying to ensure satisfactory supply. However, the adverse impacts of development projects are powerful public concerns. Preparations of adequate EIA reports contribute to enhancing overall effectiveness of the EIA process. A sample of 3 EIA reports relating to power development projects was examined, to identify problems and to investigate typical strong and weak points of environmental impact statements, for effective implementation of EIA in Thailand. The competent authority has a well formulated environmental legislation and EIA guidelines and uses a listing method as a key quality control instrument for accuracy and veracity of the reports. Comprehensive descriptions of the major issues and the adverse impacts were defined based on the nature of the construction and operation phases, with adequate information to inform on existing attributes and situations appearing in all critiqued samples. The most important lessons are that there was an absence or weakness in: (i) information on baseline conditions and site-specific information (ii) public participation and (iii) communication involvement of all stakeholders. Increased enforcement could be based on strong, well-written law. The establishment of an independent review committee's regulation, widespread public participation in every step of the EIA process and formulation of a code of conduct for the consultants, are strongly recommended.
\end{abstract}

Keywords: EIA guidelines, EIA report evaluation, Public participation, Energy development policy, ASEAN nations, Community trust

\section{Introduction}

With increasing environmental crises and public concerns, the Environmental Impact Assessment (EIA) process has been official prescribed as a screening practice for environmental planning and management of development or business projects (ONEP, 2010). The EIA is a key decision support tool for environmental, socio-economic and human health regulations. Globally, we share this planet with many other species of plants and animals, and it is important to sustain all types of ecosystem as each habitat supports unique forms of life. Similarly, ecosystems are a key component of the Earth's biosphere and also are a fundamental component in the well being for all. Generally, EIA refers to the formal process of impact prediction, resulting from policy, plan or activity under certain conditions. EIA must be undertaken early in the development of proposed projects and must be completed prior to precede decision to its made. Development projects are required to apply effective measures to prevent or mitigate negative environmental impacts. On the other hand, positive impacts can be enhanced and then the probability of sustainable development increased. Therefore, EIA must be an objective and independent analytical process based on accepted scientific principles and statistical methods, not a technique of promoting a proposal to the policy decision-makers.

In Thailand, according to the Enhancement and Conservation of National Environmental Quality Act, B.E. 2535 (1992), power plant projects that have a production capacity exceeding 10 megawatts per day, must gain approval from the Public Service and must submit an EIA report before submitting to the Cabinet. By the year 2009, the electric power usage totaled 29,212 MW, and the Electricity Generating Authority of Thailand (EGAT) has increased its projection for power demand growth from $3 \%$ to $4.72 \%$ in 2010 (EGAT, 2010). Moreover, the power development plan indicated that over 30,000 MW of new capacity are required through to 2021. Increasing demand of electric consumption is a major challenge for authorities trying to ensure satisfactory 
supply. And with this growing demand for energy capacity it is crucial to consider supply security and environmental sustainability, especially health risks, land use conflict, biodiversity depletion and global warming issues (Zilihona et al, 2004; Nakawiro et al, 2008; Conner and Roy, 2008).

Although the EIA process was implemented approximately 35 years in Thailand, it is still controversial; some project developers regard EIA as an undesirable burden, some seek to avoid the EIA procedure, and also some government administrators in charge of EIA view the process as a heavy burden (Pantumsinchai and Panswad, 2004). Moreover, political and financial support for EIA is low in developing countries, and environmental agencies are practically powerless compared with economic development agencies. Two key reasons for poor quality EIA reports are lack of qualified environmental experts, and insufficient time and money (Lohani et al, 1997), and Thailand is no exception in this regard. The author has experience in this EIA area and the aim in writing this paper was to identify the problems of the EIA process and to investigate typical strong and weak points of environmental impact statements for effective implementation of EIA in Thailand. Documentary research or desk study was applied to examine the current state of EIA of power development projects, both at the legal or regulatory processes and adequacy of the EIA report. The competency for examination of EIA preparation followed the criteria suggested by Lohani et al (1997), and Nadeem and Hameed (2006).

\section{Overview of project coverage, EIA process, scoping and report guideline}

The first mandatory provisions for EIA in Thailand were issued in 1975. By Section 46 of the Enhancement and Conservation of Nation of National Environmental Quality Act 1992, The Ministry of Natural Resources and Environment (MONRE) with the approval of National Environment Board (NEB), has the power to specify the type and size of projects or activities requiring EIA.

Notification of the MONRE, given on the $29^{\text {th }}$ of December B.E. 2552 (2009), specified 34 different types or sizes of projects or businesses that must be approved from Public Service, ranging from mining, development of petroleum, pipe-line transportation of petroleum and fuel oil, industrial enterprises, petrochemical, petroleum refining, natural gas separation, an industry producing chlor-alkaline, portland cement, paper pulp, pesticides and herbicide, chemical fertilizers, sugar, iron or steel, liquor and alcohol, factories that recycle waste products, power plants, expressways, highway and roads, public metal transit system, port, marinas for docking boats, land and housing, air transportation, dam, irrigation and all projects that are located in the plain area level 1 according to conclusion of the cabinet (ONEP, 2010). However, some projects are reducing their size to avoid EIA conditions, the initial environmental examination (IEE) with less environmental impact will be required based on existing rapid assessment methods of secondary data and expert judgment.

Five steps and corresponding tasks of the EIA process are proposed and public participation is included in all steps as well. (1) Screening comprises of initiation of the project, site evaluation and local authorities involvement; (2) Scoping comprises of site selection, scope of EIA and public and stakeholders' involvement; (3) Report preparation comprises of consultant selection, draft report preparation and data acquisition/public input/opinion; (4) EIA review comprises of final report preparation, EIA expert panel review for private project submitted to permitting authority, for government project submitted to National Environmental Board and to the Cabinet; and (5) Monitoring comprises of project owner submitted report, follow-up by permitting authority and monitoring by a third-party.

Guidelines for preparation of the EIA report for a project or activity which may seriously affect community with respect to quality of environment, natural resources and health comprises of (1) Substantial matters including (1.1) summary report containing description, location and alternative location and operational method of the project or activity report on impact which may significantly affect the environment, protection and remedy thereof and investigation and examination of environmental impact and conclusion. (1.2) The main report contains introduction, location of the project or activity, description, existing environmental conditions and evaluation of the alternatives, measure for protection and remedy of environmental impact and compensation and summarizing table. And (2) Documents and evidence to be submitted include main report, summary report, front cover and inside cover of EIA report, Certificate for preparation of EIA report, copy of permission to be preparer of the EIA report, list of the persons preparing the EIA report, and form for submission (). For larger scale projects which may cause significant impacts, the EIA report must be submitted to the Office of the Natural Resources and Environmental Policy and Planning (ONEP) to be reviewed and for recommendations to be made. EIA have to be prepared by a consulting firm which is registered by ONEP.

In the approval process for EIA of a private sector project, 75-days are the required minimum timing of processing. The Environmental Impact Evaluation Bureau (EIEB) must examine the report within 15 days then the EIEB reviews and makes preliminary comment on the EIA report within the next 15 days. And then the EIA 
report together with the preliminary comment will be approved by the review committee who will consider the report within 45 days. There is no limitation on the period of report review for government or state enterprises projects. The authorized agency must prepare the EIA for such projects and such report will be filed with the National Environment Board for its review and comment and then submitted to the Cabinet for consideration.

\section{Case study: The EIA reports of power development projects in Thailand}

A sample of 3 EIA reports relating to power development projects has been investigated specifically to concentrate the review. Project owners were both state owned enterprises and private power producers. All of these projects are variably located in significant economic regions of Thailand. EIA professional consultants consist of various renowned specialists in related fields.

\subsection{Legislation and Guidelines for Preparation and Review of EIA Reports}

The official contents of an EIA report and preparing system are well-organized in Thailand. The EIA reports must be submitted to the ONEP to be reviewed and given a recommendation and these reports also must be prepared by a consulting agency which is registered by the ONEP. Well established environmental legislation and EIA guidelines such as rules, procedures, acceptable methods and how to prepare the report, guidelines for evaluation of health impact assessment, guidelines for consultation with the public and interested parties, forms of the report, certificate for report preparation, list of the persons preparing the report, and form for report submission, have been clearly identified and formulated. The ONEP uses a listing method as a key quality control instrument for accuracy and veracity of the reports. However, information providing for the general public regarding EIA techniques and any relevant factors affecting environmental quality, display on the ONEP website (http://www.onep.go.th/eia/ENGLISH/eia_eng_index.htm), are limited.

\subsection{Description of Development Project, Environmental components and their values, and Baseline conditions}

All the critiqued EIA reports presented a comprehensive description of the power plant project through construction and the operation phases with a justification that "all procedures have been conducted on the basis of maximum production efficiency, minimized adverse environmental and health impacts or safe operation, high percentage of local participation and public acceptance." Project description and details, physical and biological environmental resources, ecological system, value for human being utilizations and value for quality of life; has been reported on the basis of secondary data include; design and construction, manufacturer's specifications, chemical reagent, production procedures, location and topography, land use, climate, soils feature, geological characteristics and earthquake, ambient air and noise quality, rainfall, runoff and drainage, underground water and surface water quality, forest and wildlife, aquatic flora and fauna, aquaculture fishery utilization, agriculture, industry, transportation, energy and electric power, socio-economic, scenery and tourism, historical and archaeological aspects.

These topics presented in the EIA reports are adequate information to inform on existing attributes and situations. Similarly, base maps for spatial data, appropriate maps, graphic and flow diagrams were used to summarize this information. In addition, the report was prepared through continuous and harmonious coordination with the project owners, consultant agency, local community, stakeholders and regulators.

The reliability of data is questionable because each specialist has compiled data on its own. Whereas the baseline conditions related to ambient air quality, ambient noise, ground water and surface water quality conditions, soils, local flora and fauna, should have been conducted by using field-taken samples from the project site analyzed by standard environmental analyzing laboratories. Results of consultant interviews revealed that lack of efficient data and appropriate information availability of baseline conditions. Consultant agencies are often concerned about these limitations because it takes too much time, resource use and expenditure for data collecting about baseline condition of site-specific information for each EIA study.

\subsection{Identification and Evaluation of Key Impacts}

Descriptions of the major issues and the adverse impacts have been defined based on the nature of the construction and operation phases of each type of power plant project. International standards and criteria include; WHO, US Environmental Standards, Thai Environmental Regulations, have been reviewed. Social and health impact assessments were also defined. Various predictive methods and impact prediction includes a number of stated assumptions that affect the predicted impacts, their probability of occurrence and degree of impact, were also significantly identified. Unfortunately, given documentation of the cause and effect associations between proposed project activities on the environmental components, and identification of secondary or higher order effects, were insufficient or out-of-date information. 
Although it has been prescribed as a guideline for consultation with the public and interested parties in the EIA process that all stakeholders should be referred to in conducting surveys and in consultation, in practice the public involvement appears predominantly unipolar and little effort taken in reaching out to all stakeholders. Local community was also consulted on a limited scale and not covered by such qualitative research techniques during EIA.

\subsection{Alternatives and Mitigation of Impacts}

Acceptable evaluation methods, and a comprehensive listing of environmental factors to be considered, were identified. Descriptions of all the environmental protection measures were considered to mitigate or offset damaging environmental impacts from project activities. Information on techniques used in each environmental protection measure including information regarding its prior effective use, the range of environmental conditions under which it is effective, and the level of skill required to operate or maintain the technology, also appeared in the EIA report. Only direct or explicit costs and benefits for each recommended environmental protection option developed to resolve a significant environmental issue were defined. Whereas the adverse impacts and consequences of a proposal which can occur far beyond the boundaries of project location together with the implicit cost of those impacts, were not accounted for in economic analyses of project feasibility. In addition, fewer alternatives either to development intervention or to the site of the project was discussed but usually only considered informally, both for the process and site and not included in the EIA reports.

\subsection{Environmental Monitoring Plan and Communication of Results}

The measurable environmental indicators were clearly defined. For the reviewed EIA reports, specified questions were found to be addressed by the monitoring program. So too, well proposed action plans for environmental and ecosystem rehabilitations, public participation and local health care covering monitoring procedure, timing and duration, responsible agency and estimated budget. The outline and presentation of the report depended upon the experience of the consultant agency whereas the number of chapters, the format of the EIA report and the guidelines about the contents were already set up by the ONEP. Usually, the results have been communicated in a form which presents a positive image of the project. The baseline data regarding environmental ecosystem characteristics and cultural socioeconomic aspects have been predominantly obtained from both site-specific data and various secondary data, and always up to date sources. However, the challenges of participation in community-based monitoring both ecological and socioeconomic issues are necessary within construction, commissioning and electricity generating phase of power development.

\section{Discussion and Conclusion}

Even if all reviewed EIA reports were comprehensive, well organized and clearly written in plain language (non-experts) but also to appropriate technical standards. Several typical weaknesses need to be remedied for effective implementation of EIA in Thailand. Currently, some project developers consider EIA to be a necessary evil that they have to implement in order to obtain their Construction Permit (Pearmain, 2008). The EIA reports are usually prepared by private consultants hired by the project developers within minimum time and cost. The EIA consultants may also be careless because of lack of up-to-date data about baseline conditions relating to physical and biological ecosystems, and socio-economic aspects. Poor methods are being used to identify and assess the magnitude of adverse impacts, particularly in health risk assessment. Also, there is often insufficient communication with all stakeholders. Therefore, some consultants seek to use data borrowed from other reports with little site-specific information that also generates large volumes of reports to conceal the limitations of, and lack of, site-specific relevant details (Pantumsinchai and Panswad, 2004).

Public participation in the process is crucial, particularly in such a multicultural sensitive region as the southernmost parts of Thailand (Chesoh, 2010). Weak public participation and unsatisfied communication produce many limitations, both legally and in practice, and result in limited knowledge and uneven distribution the project information to the local population, and then the local community mistrusts the EIA report and violent protests have been happened in such cases. So, how can all stake-holders participate effectively in every step of EIA process? Public media are the preferable means for conveying information, including information of measures of mitigation of adverse environmental impacts, to people living adjacent to the project site. Review is made by the concerned officials of the authority in charge of the EIA approval but without local expert panels and local administrative organization officers. Moreover, the EIA reviewers themselves are not experts in all areas, they work under pressures of time limits. The allowances they are paid for this important work in reviewing and approving EIA reports is tiny compared to the billions of dollars spent on the development projects (Pantumsinchai and Panswad, 2004). 
Although the power development is very necessary, it is essential to address widespread public environmental concerns. Therefore, to decrease conflict within Thai society, increasing both enforcement based on strong well-written laws to prevent avoidance and widespread public participation at every step of the EIA processes, is the best option (Stampe, 2009). In order to ensure transparency and quality, the EIA review and approval should be assigned to independent review committees. All of strategic environmental frameworks, improvement of the EIA process, increase roles of community organizers, clear legal dispute processes and a written code of conduct for the consultants, are required.

\section{References}

Chesoh, S. (2010). Community Perception, Satisfaction and Participation toward Power Plant Development in Southernmost of Thailand. Sustainable Development, 3 (2): 84-88.

Connor, A. and Roy C. (2008). Electric Power Plant Emissions and Public Health. American Journal of Nursing, 108 (2): 62-70. doi:10.1097/01.NAJ.0000310342.98495.b6, http://dx.doi.org/10.1097/01.NAJ.0000310342.98495.b6

Electricity Generating Authority of Thailand (EGAT). (2010). Summary of Thailand Power Development Plan 2010-2030. [Online] Available: http://www.egat.co.th/thai/files/Report\%20PDP2010-Apr2010_English.pdf (10 May 2010)

Lohani, B., Evans J. W., Ludwig H., Everitt R. R., Carpenter A. R, and Tu S.L. (1997). Environmental Impact Assessment for Developing Countries in Asia. Asian Development Bank (ADB). Vol. 1- Overview. pp. 356. [Online] Available: http://www.adb.org/documents/books/environment_impact/env_impact.pdf (10 May 2010)

Nadeem O. and Hameed R. (2006). A Critical Review of the Adequacy of EIA Reports-Evidence from Pakistan. World Academy of Science, Engineering and Technology 23. [Online] Available: http://www.waset.ac.nz/ (10 May 2010)

Nakawiro, T., Bhattacharyya, C. S., and Limmeech, B. (2008). Expanding Electricity Capacity in Thailand to Meet the Twin Challenges of Supply Security and Environmental Protection. Energy Policy, 36, 2265-2278. doi:10.1016/j.enpol.2008.03.002, http://dx.doi.org/10.1016/j.enpol.2008.03.002

Office of Natural Resources and Environmental Policy and Planning (ONEP). (2010). Environmental Impact Assessment (EIA). [Online] Available: http://www.onep.go.th/eia/ENGLISH/eia_eng_index.htm (20 May 2010)

Pantumsinchai P., and Panswad, T. (2004). Improvement of EIA Process in Thailand. [Online] Available: http://www.eeat.or.th/articles/articles.htm (20 May 2010)

Pearmain S. (2008). Environmental Impact Assessment in Thailand. [Online] Available: http://www.environmental-expert.com/ (20 May 2010)

Stampe, W. John. (2009). Lessons Learned from Environmental Impact Assessments: A Look at Two Widely Different Approaches - The USA and Thailand. Transdisciplinary Environmental Studies, 8 (1): 1-7.

Zilihona I. J. E., Niemelä J. and Nummelin M. (2004). Effects of a Hydropower Plant on Coleopteran Diversity and Abundance in the Udzungwa Mountains,Tanzania. Biodiversity and Conservation, 13(8): 1453-1464. doi:10.1023/B:BIOC.0000021325.90554.0b, http://dx.doi.org/10.1023/B:BIOC.0000021325.90554.0b 